\title{
A Brief Evaluation to Identify Level of Satisfaction of Art Therapy with Undergraduate Ukrainian Students
}

\author{
Theresa Van Lith $^{1}$ - Lindsay Bullock ${ }^{1}$ - Iryna Horbal ${ }^{2}$. \\ Alexander Lvov ${ }^{3}$
}

(C) Springer Science+Business Media New York 2017

\begin{abstract}
A particular political and social mindset toward mental health support has impacted how and why people seek counseling and therapy in Ukraine. Although a relatively small and developing field, art therapy is beginning to provide a means for assisting cultural and identity development for young adult Ukrainians during a time of civil and political unrest. Cross culturally, art therapy has been found to assist young people in developing a healthy self-concept by providing them with a realistic and less defensive view of themselves and their environment. This paper evaluates the development of art therapy in Ukraine, and examines the practice of art therapy with undergraduate Ukrainian students. First, it details findings from a questionnaire with university students to determine their perception of art therapy. Analysis of these findings resulted in identifying their level of satisfaction toward art therapy, and common reasons why art therapy was sought. Second, the article provides a brief vignette to demonstrate how art therapy was used with undergraduate university students to assist with processing negative memories associated with living under the Soviet era. Finally, the article concludes with a discussion about how to tailor art therapy so that instead of being perceived as a cure it promotes self-care, thereby helping overcome the stigma associated with seeking therapeutic services.
\end{abstract}

Keywords Art therapy $\cdot$ Counseling $\cdot$ Ukraine $\cdot$ University students $\cdot$ Cultural identity

Theresa Van Lith

tvanlith@fsu.edu

1 Department of Art Education, Florida State University, William Johnston building, 143 Honors Way, Tallahassee, FL 32306-1231, USA

2 Psychological Department, Lviv Ivan Franko National University, Lviv, Ukraine

3 Department of Acute States and Rehabilitation, Lviv Regional State Clinical Psychiatric Hospital, Lviv, Ukraine 


\section{Introduction}

After inviting international art therapists to assist with a study involving clients' perceptions of art therapy, a conversation began between the first author and a Ukrainian art therapist, Iryna Horbal, about how art therapy was practiced in Ukraine. To gain further understanding about this, the second author used social media to connect with other Ukrainian art therapists. As a result, several online conversations occurred, in which the second author enquired into the rich cultural traditions of art making, Ukrainian understandings of therapy, and how art therapy has been practiced in Ukraine. To formalize the inquiry, Iryna Horbal and Alexander Lvov implemented a questionnaire seeking perceptions of art therapy from students receiving counseling at a Ukrainian University Counseling Clinic. Horbal also collected clients' artworks and their responses from attending a Ukrainian art therapy workshop that focused on processing negative memories associated with living under the Soviet era. The main intention of this article is to explore the ways in which art therapy can address the socio-politicoeconomic issues impacting young people currently.

\section{The Impact of Politics on Mental Health}

The political and civil upheaval throughout the twentieth and twenty-first centuries severely impacted the treatment of and support for mental health issues in Ukraine. For instance, prior to the early 1900 's, the use of psychoanalytical therapy, particularly influenced by Sigmund Freud, was prevalent in the Soviet Union (Yakushko 2005; Yankovsky 2011). However, as Bowen (2011) explained, when Joseph Stalin came to power, psychotherapy was characterized as going against the principles of a communist Soviet state, because it emphasized an individualized rather than a collectivist mindset. Subsequently, all forms of psychotherapy were banned and, instead, state authorities began using mental health services as a tool to repress political dissidents by mandating involuntary psychiatric admissions (Yakushko 2005; Yankovsky 2011).

During this period, as Targum et al. (2013) highlighted, educational institutions emphasized a psychobiology model of treatment for mental illness. For example, Soviet scholars Ivan Pavlov and Lev Vygotsky were known for their contributions to neuroscience, but little was mentioned about the application of their theories to counseling (Yakushko 2005). This meant that the philosophies encouraged in psychiatric training were of a certain political influence, with the aim being to "preserve the moral, political, and ideological safety of Soviet citizens" (Targum et al. 2013, p. 43). Moreover, psychiatrists were known to have what Yankovsky (2011) referred to as an "adversarial" (p. 39) dynamic with their patients, creating more of an authoritarian connection to helpseeking for mental health concerns.

More recently, the influence of western media has brought about an interest in therapeutic approaches supporting mental health, such as well-being oriented practices and psychological health prevention programs (Yakushko 2005). But, while western models of mental health practice may have begun to influence some urbanized Ukrainians, a long tradition of using indigenous forms of counseling in rural parts of Ukraine has remained relatively constant. These spiritual practices include the use of herbs, energy healing, and affirmations administered by local non-official healers, who were more trusted than the authoritative regime of medical doctors under the Soviet system (Yakushko 2005). Other spiritual models of 
counseling include the integration of Slavic Orthodox church belief systems with psychology, referred to as "Christian counseling", which translates in Russian to "soul care" (Bowen 2011).

There has also been a recent resurgence for promoting psychotherapy and a decrease in emphasizing behavior and cognitive modification therapies, resulting in training institutions now teaching multiple schools of thought, which might include psychoanalytic, transpersonal, Jungian, Gestalt, body-focused and humanistic approaches, as well as music and art therapies (Havenaar et al. 1998; Sosland 1997).

\section{Art Therapy as a Developing Mental Health Profession}

In Ukraine, the practice of art therapy as a form of psychotherapy is still in its early stages, but the high level of interest has spurred the growth of training options. For example, Dr. Margaret Hills de Zarate of Queen Margaret University in Edinburgh has been instrumental in developing an art therapy training program in conjunction with the Ukrainian Psychotherapy Association (ECArTE 2015). These post-graduate courses are offered through the Ukrainian Umbrella Association of Psychology (UUAP) under the European Association of Psychotherapy (EAP). This program began in 2011 and consists of 9-10 semesters each involving between 5 and 7 days. During the program, students take part in theoretical and practical sessions, supervision, and client practice. Acceptance into the program requires higher psychological, medical or other connected education to supplement the program. Upon completion, each student receives a certificate providing them with a credential for being an art therapist. However, those seeking a master's degree in art therapy tend to relocate to either the United States or United Kingdom (ECArTE 2015).

Furthermore, the Ukrainian professional art therapy association, founded in 2003, provides art therapy education for Ukrainian psychologists (Vozneseska 2015). So far, the association has held approximately 12 annual art therapy scientific-practical conferences, as well as educational training seminars and workshops (Vozneseska 2015). Reportedly, the association has produced numerous articles and books about art therapy (Vozneseska 2015). Yet, ongoing political and economic crises have meant limited resources being available to help advance the field as a professional body (Stoll 2005). Tuchynska (2015), a local Ukrainian reporter, had a similar opinion, explaining economical resources as a key reason for lack of development in the field.

Art therapy in Ukraine as a profession in its own right still requires formal acceptance and a qualifying credential to help increase its perceived credibility within the community (Arrington and Yorgin 2001; Stoll 2005). For instance, American Art Therapist, Dorris Arrington (2005) found that health professionals working in state shelters and orphanages in Kiev had never heard of art therapy, or the concept of using art as a therapeutic tool. Still, Canadian Art Therapist, Olena Darwych, who visited Ukraine for multiple projects $(2009,2013)$, suggested that while art therapy is in a stage of infancy, art is a universal language that is significant to Ukrainians who have historically been passionate about art (Darwych 2013).

Ukrainian art therapist Horbal explained some of the common misperceptions toward receiving art therapy among the Ukrainian community. For instance, misunderstandings might occur when art therapists introduce the concept of therapy. As Horbal explained, sometimes it is better to introduce yourself as a clinician, not an art therapist "to avoid the client perceiving the art therapist as a person who heals crazy patients in a psychiatric hospital". Horbal also noted that a client might also be confused in that treatment by a psychotherapist typically involves the use of medicine or medical procedures. Furthermore, clients might perceive the psychologist's 
practice as "a way to organize life better", and may think that life-long problems can be solved in just one or two meetings.

To help resolve some of these issues, Horbal suggested that when beginning art therapy, time should be spent on helping the client understand that they do not need artistic skill and to demonstrate how the therapeutic process works through art making. As Horbal explained, until recently art therapy was not sought out, as "people were not used to talking to strangers about their troubles" and even less familiar with using art-making to express feelings. Therapy may also take the form of integrating spiritual practices and beliefs in order to accommodate individuals' ideas about the purpose of therapy, as some of the older population have traditionally sought advice from priests for problem-solving about mental health issues, and were raised in religious families where this was the norm.

Based on such circumstances, in Ukraine the beginning of sessions may differ from western practices, whereby it may take a lot of time to gain trust and explain the peculiarities and necessities involved in the art therapy process. Horbal emphasized that this rapport building stage is of utmost importance due to the longstanding mistrust in authority and associated fear toward opening up feelings. According to Bowen (2011), these concerns around confidentiality are warranted, as many Ukrainians still remember family members being arrested or jailed for speaking too openly.

\section{Perceptions of a Ukrainian Art Therapy Program}

In order to understand how art therapy was practiced and perceived by recipients, Ukrainian art therapists Horbal and Lvov distributed a questionnaire about perceptions of art therapy to Ukrainian university students who were receiving art therapy sessions at a University Counseling Clinic. The purpose of the questionnaire was to evaluate where misconceptions or misunderstandings might exist between these clients and their expectations of the services they might receive from art therapists. Additionally, the intention was to learn what motivational factors were causing students to seek out art therapy. Another goal was to also identify salient features of the art therapy experience from the client's perspective, including their level of satisfaction and whether it met their expectations.

Students from Rivne State Humanity University were notified of the study during their undergraduate psychology classes and via email, and were assured their identities would remain anonymous. In order to participate in the survey, they needed to be a client of the art therapy clinic on campus. The art therapists working at the clinic had been trained through the Ukrainian Umbrella Psychotherapy Association or affiliated art therapy organizations.

The questionnaire sought to gather evaluative information about the clients' levels of satisfaction of the services they were receiving at the art therapy clinic. The following questions were provided to the clients in Ukrainian. The first part of the questionnaire requested background information such as age, gender, cultural background, state and country currently residing, type of service currently receiving, length of time currently receiving art therapy, and reasons for seeking mental health support.

Then six questions were included from the 'Client Satisfaction Questionnaire' (CSQ-8; Larsen et al. 1979), which was designed to assess client satisfaction with treatment and their perspective on the value of services received (Attkisson and Greenfield 2004). However, the wording was slightly modified to orient the questions to focus specifically on the art 
therapy services they were receiving. This helped to ensure the participants' responses reflected their perceptions about how art therapy had assisted in resolving issues and their levels of satisfaction.

The students were then asked to respond to these questions using a 4-point satisfaction Likert scale with the options Excellent, Good, Fair, and Poor. The following questions were presented: "How would you rate the quality of art therapy you have received?", "In an overall, general sense how satisfied are you with the art therapy you have received?", "To what extent has art therapy met your needs?", "Has the art therapy you received helped you to deal more effectively with your problems?", "If you were to seek help again, would you come back to art therapy?", "If a friend were in need of similar help, would you recommend art therapy to him or her?".

Participants were then asked a final question: "Which would be the biggest barrier to receiving art therapy?" Please rank 1(biggest) - 6 (smallest), the following options: access, costs associated, the stigma attached to seeking help, the stigma attached to mental illness, making a commitment to therapy, the perception that one cannot change through therapy, or other (please state). This final question was developed out of work by Henshaw and Freedman-Doan (2009) who argued that the barriers to receiving mental health services mainly involved those stated above.

To evaluate the responses, the totals for each question were scored and calculated using percentages.

\section{Responses from the Questionnaire}

Horbal and Lvov collected a sample consisting of 90 participants ( 80 female, 10 male), aged between 17 and 20 years, and all identifying as Ukrainian. They had been attending the art therapy clinic for a range of between 2 months to 2 years. The questionnaire findings revealed that students had learned of the art therapy clinic through information they received from university teachers, friends, classmates, a volunteer project, or previous counseling experiences. Some respondents self-referred to art therapy, while some were currently studying art therapy and had sought it out as part of their professional development.

The main reasons indicated for why the participants were receiving art therapy were: selfdissatisfaction, family problems, unstable relationships with a loved one, inner tension, as well as the need for help with personal problem-solving. Overall, participants noted the following positive aspects of engaging in art therapy: increase in self-esteem, self expression and ability to control emotions, as well as an openness to receive new experiences and feel more active in life.

According to the results from the first question, when asked how they would rate the quality of art therapy received, $45 \%$ of participants indicated it was 'excellent', $44 \%$ reported it was 'good', and $11 \%$ responded 'fair'. This spread of results was further supported by how participants indicated their level of satisfaction with receiving the kind of art therapy they wanted, with $33 \%$ of participants testifying 'yes, definitely'; 56\% reporting 'yes, generally'; and $11 \%$ responding 'no, not really'. The third question helped to clarify the extent that art therapy had met the participants' needs, which revealed that the majority (67\%) felt 'most of my needs have been met', followed by 'only a few of my needs have been met' (22\%), while only $11 \%$ indicated that 'almost all of my needs have been met'. When considered together, these findings indicate that, although most participants were satisfied and felt their meets had been met, there was still much room for improvement.

In gathering an understanding as to whether the art therapy that the participants had received was helping them deal more effectively with their problems, the majority (89\%) indicated that 'yes, they helped a great deal', with $11 \%$ responding 'no, they didn't really help'. 
This overall positive attitude toward art therapy as a method to help participants manage their issues more effectively was also evident in participants' responses in regard to whether they would come back to art therapy if they were to seek help, with $56 \%$ responding 'yes, I think so' and 44\% 'yes, definitely'. Moreover, there was a high level of likelihood that they would recommend art therapy to their friends if they were in need of similar help, with $56 \%$ reporting 'yes, I think so' and 44\% 'yes, definitely'.

There was a relatively even distribution of how participants responded to the final question: 'Which would be the biggest barrier to receiving art therapy?'. The highest number of respondents $(23 \%)$ selected 'the perception that one cannot change through therapy', which was closely followed (22\%) by 'the stigma attached to mental illness', and (21\%) 'the stigma attached to seeking help'. In contrast, the two least common barriers identified were 'access, costs associated' (18\%), followed by 'making a commitment to therapy' (16\%). No participants indicated anything under 'other' as possible barriers.

\section{Individual Experiences of a Ukrainian Art Therapy Workshop}

After exploring the perceptions of art therapy among Ukrainian university students, Horbal provided a vignette of a Ukrainian university-based art therapy workshop. This vignette provides case examples of individual art therapy experiences by some of the students who attended the workshop. Pseudonyms have been used to protect the clients' identities.

The workshop was organized using plastic toys, which served as a representational reminder of their lives under the Soviet Union, when only these types of toys were available. While most of the clients responded negatively to the memories evoked by the toys, there was also a realization that this was a part of their life-story. Therefore, the main focus of the art therapy workshop was to help the clients accept negatively associated memories and parts of the self that they perceived as negative. The clients were invited to use toys and a range of 3dimensional materials to create a visual representation of likes and dislikes about their memories of this time, with particular emphasis on their symbolic relationship to color.

Kateryna used plastic dishes, a small piece of yellow soap and dark colored fabric to depict her dislikes (see Fig. 1). She noted that the dark color was used as a symbol of a time in mourning. Kateryna described that the stitched up mouth represented how people did not have the freedom to say: "I don't like it!, because nobody could do anything to change it in a more positive way".

Hanna depicted her dislikes (see Fig. 2) by placing several objects on a cord, which were reminiscent of her childhood during the Soviet era. She placed a plastic bag, because her grandmother would wash the plastic bags and hang them on a cord to dry so they could be used again. The foam curler was added to represent how women would sleep in them during the night to curl their hair, and a foam ribbon was added to represent how in the winter materials were squeezed into the apertures of old windows to keep the warmth in. Hanna also chose a clip from the "ugly soviet bra" that she disliked as "women looked horrible wearing them, losing all their attractiveness and femininity".

Nadya depicted a snake as a symbol of her dislikes. She explained that the snake was "striking and attractive [multiple colours], but it is also dangerous, may bite and can cause death". For the artwork depicting her likes, Nadya drew an egg, with a distinctive yellow yolk, as a symbol of germination and the conception of something new (see Fig. 3).

At the end of the workshop, to help integrate the group as a whole, members were asked to create an artwork together based on the theme 'Integration by color' (see Fig. 4). Each 
Fig. 1 Kateryna's dislikes

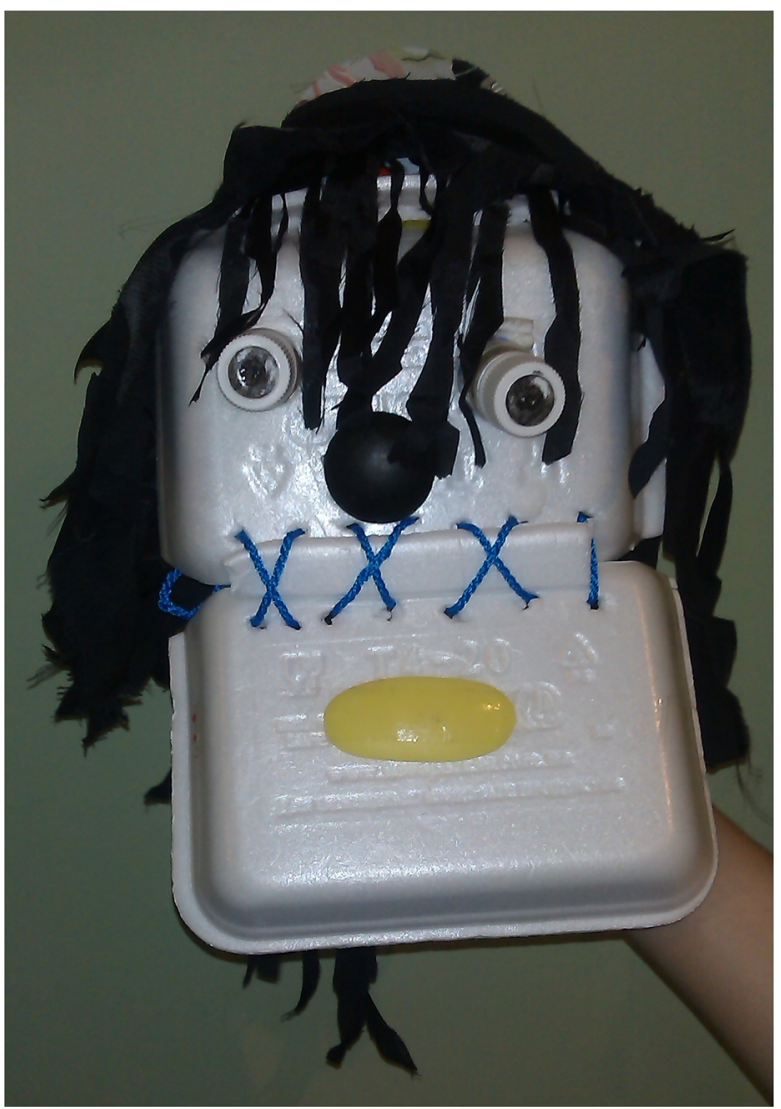

participant was asked to choose only one color, from a selection of yellow, purple, blue, green, red, and brown, and to reflect his or her experience of the workshop. On reflection of the artwork, the clients expressed satisfaction, as well as the reduction of anxiety and other negative feelings, together with a positive attitude to other group members.

Observing the clients' responses from this workshop, Horbal explained that the most common issues for which university students received art therapy were "low self-esteem" and "personal uncertainty". This also corresponds to the findings of the questionnaire. Horbal disclosed that many students experience self-doubt, questioning their professional choice and likelihood of success, as well as presenting with concerns around their cultural identity. These concerns result in increased levels of anxiety and stress that Horbal described as being the result of "the socio-political crisis and instability in the country".

\section{Using Art Therapy to Assist Cultural Development of Identity}

As art therapy continues to advance in Ukraine, a question remains as to whether art therapy might be able to serve young people as they try to navigate their way toward developing their cultural identity. In art therapy, reviewing and reflecting on one's artwork enables clients to understand underlying motives and helps in gaining self-awareness, which leads to mastery over the development of one's identity (Linesch 2016; Parisian 2015). According to Mauro 
Fig. 2 Hanna's dislikes

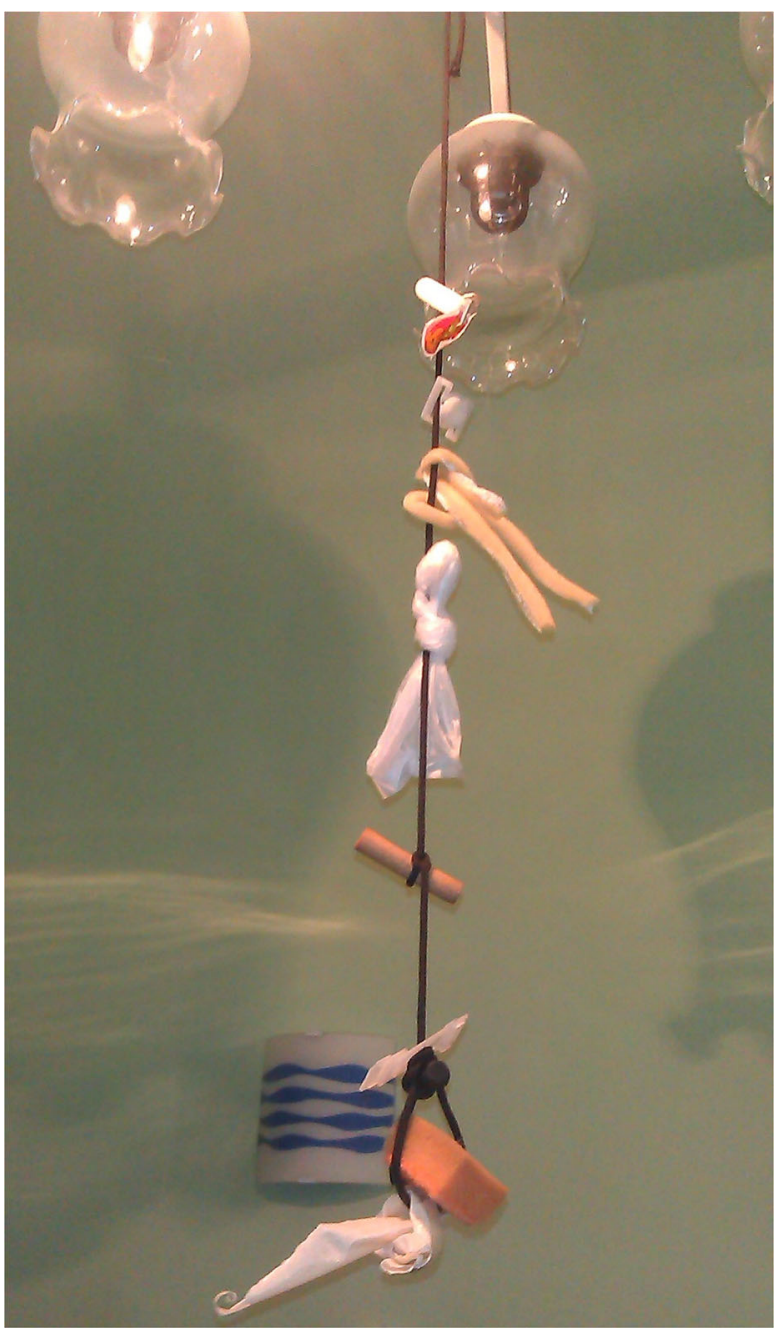

(2005), through visual expression a client can communicate who they are, how they feel, and how they identify with their specific culture, thereby, providing them with a realistic and less defensive view of themselves and their environment. This benefit of acquiring awareness of one's cultural identity has been associated with "developing cohesive psychological integrity" (Mauro 2005, p.135), and, therefore, having a healthy self-concept.

Through the art-making process, the art materials, and the relationship with the art therapist, multiple layers of personal meaning are explored, then acknowledged, and finally reintegrated to create a healthier self-concept. For example, McGann (2006) used self-portraits with adolescent African American females in their learning to embrace and accept their cultural identity. Parisian (2015) found that symbolic imagery through art-making helped to reflect a sense of disconnect for an adolescent boy who had Filipino heritage, but an American upbringing. Through art therapy the boy was able to integrate both cultures into his identity, which resulted in him being more socially and emotionally adjusted at school as well as at home. Other art therapy prompts known to nurture one's cultural identity development include: 


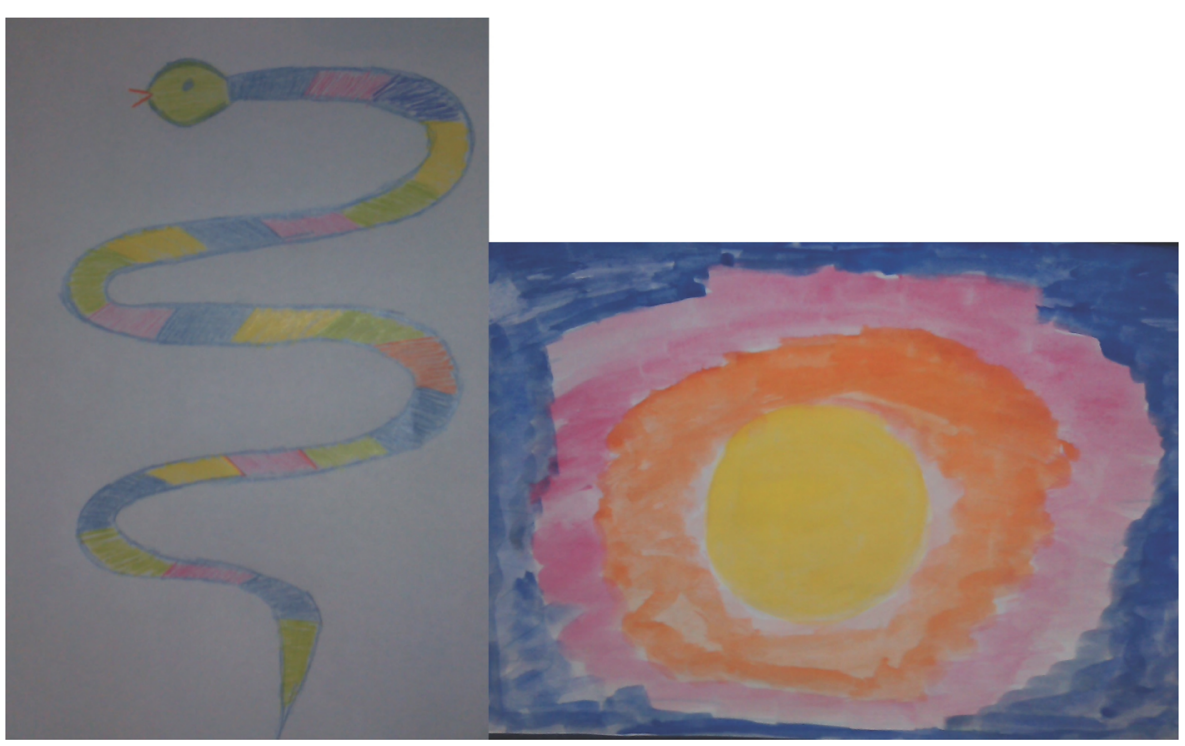

Fig. 3 Nadya's dislikes and likes

mask making (Miller 2012), doll making (Feen-Calligan et al. 2009), and self-representational puzzles (Linesch 2016).

\section{Art Therapy to Assist in Ukrainian Identity Reformation.}

Since Ukraine gained independence in 1991, the shift from the collectivist socialist mindset of the Soviet era toward western capitalist neoliberal individualism has created identity issues for much of the Ukrainian population (Yankovsky 2011). Riabchuk (2015) posited that this division in cultural identity has proven problematic for the younger population, who are now trying to reconstruct the previous value systems in order to develop their own national identity that interconnects with global influences. This theory is reflected in the previous examples of the undergraduate students.

Nikolayenko (2011) suggested that, as a result of the social circumstances for the student populations, it is evident that there is a lack of self-confidence and a high sense of hopelessness. Yakushko and Sokolova (2010) determined that Ukrainian college students with positive self-esteem also have a sense of hope for the future. However, many students hoping for a successful career may still feel constrained, because during the Soviet era career paths were determined by nationality, parental influence, membership in the Communist party, or personal networks (Yakushko 2007; Yakushko and Sokolova 2010).

As demonstrated in the case vignette, art therapy was illustrated as one possible resolution to this identity conflict amongst Ukrainian students. The results of the questionnaire provided to Ukrainian university students revealed overall satisfaction with the service, and that they felt they were better able to handle their problems effectively. In accordance with Mauro (2005), Linesch (2016) and Parisian (2015), the participants seemed to be using art therapy to assist in identity development through developing self awareness, as well as awareness of themselves in relation to others, their culture and their surroundings (FeenCalligan and Nevedal 2008; Wood 2013). 
Fig. 4 Group artwork

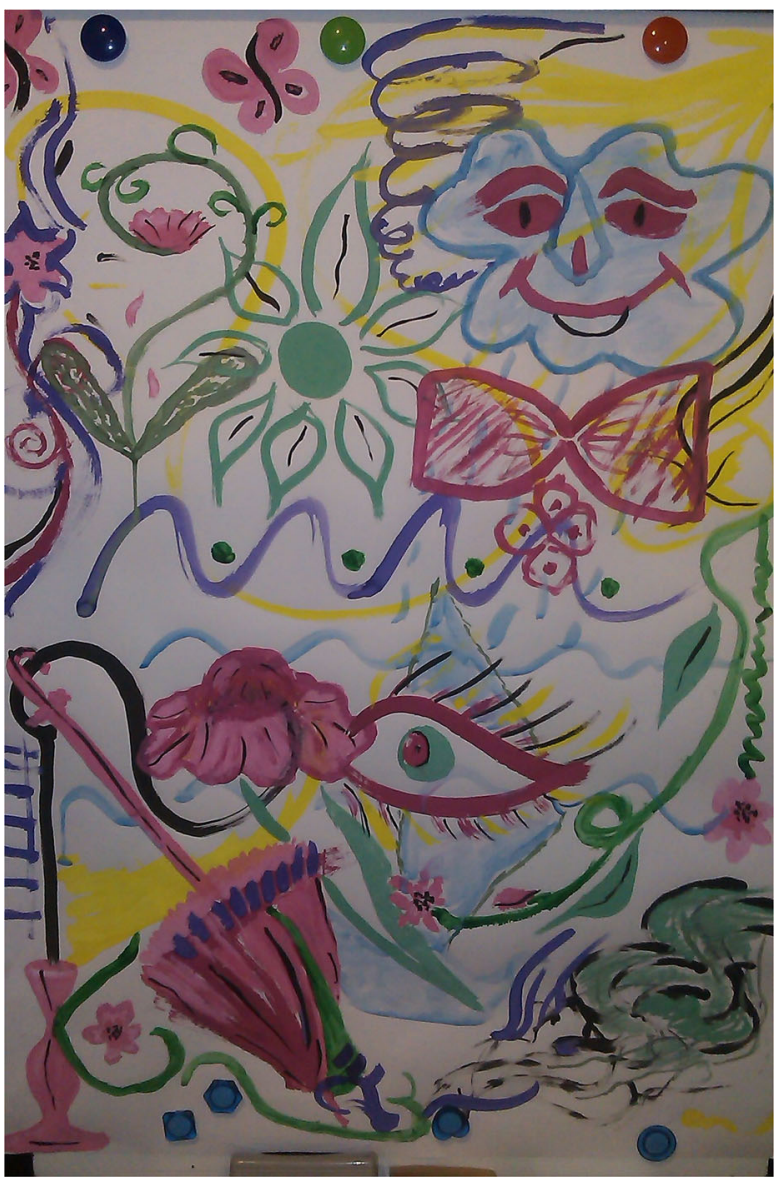

However, the relatively evenly distributed responses to the identified barriers toward seeking art therapy could pose problems to the use of art therapy for identity resolution. The ambivalence suggested toward therapy and the field of mental health was in line with Bowen's (2011) notion that therapy and seeking it out still has an image problem in this part of the world. Referring back to previous literature reveals that individual change through therapy and stigma towards mental illness and therapy still dominates attitudes in much of Ukraine (Bowen 2011; Tuchynska 2010; Yakushko 2005; Yankovsky 2011). For example, under the Soviet system, clients were encouraged to surrender healthcare responsibility to the state, and medication was stressed as the dominant means for change. As Tuchynska (2010) posited, art therapy as a psychotherapeutic treatment might still be frowned upon in some parts of Ukraine. For instance, in Ukraine's largest psychiatric institution, Kyiv's Ivan Pavlov Mental Hospital, "pills are still considered better than art" (Tuchynska 2010).

Due to a lingering mistrust of the psychiatric field, a stigma still remains toward seeking help for mental health issues. Past use of forcible treatments and a paternalistic approach with patients has led to a delayed release of patients, expensive medical bills, or families left with long-term care without resources (Bowen 2011; Yakushko 2005). While it may be the case that 
mental illness still involves discrimination and carries stigma in many countries, the repressive past of Ukraine means that mental health practitioners face even larger hurdles in promoting help-seeking attitudes and behaviors (Yankovsky 2011).

In Ukraine, a dichotomous tension still exists as to whether the state takes care of one's mental healthcare or if it is an individual's responsibility (Yankovsky 2011). In theory, the state funds health care and the emphasis is on hospital-based treatments, but due to an economic shortage, patients still pay for these services. This has resulted in few private clinics and healthcare services, which are predominantly situated in the cities.

Yankovsky (2011) suggested that the younger generation who are more influenced by western models of healthcare are more likely to make the shift toward taking charge of their future and, therefore, using therapy to make personal changes when needed. Although reforms in Ukraine are in place to move toward community-based treatment services and to develop a wider availability of health insurance options, creating a uniform model still remains tied up in political disputes (Yankovsky 2011).

A fuller understanding of why participants in this study ranked the stated barriers in the way they did would be needed to provide a more conclusive understanding of their responses. This would also assist in developing a strategy for promotion and education about what art therapy is and what potential it has to offer to the wider public.

\section{Conclusion}

Through this article, we have explored the developing practice of art therapy in Ukraine, and investigated how art therapy has been used with Ukrainian university students. In this process, we discovered how art therapy might be useful in assisting Ukrainian university students to express and process identity issues caused by past and continuing civil and political unrest. Indications from the questionnaire revealed that art therapy helped clients address personal and relationship issues, expressing that they did improve in managing and regulating their emotions, experienced enhanced self-esteem, and became more open to new life experiences.

Using art therapy for such purposes is somewhat unique because it requires looking at an individual's presenting issues within a wider socio-politico-economic context. This includes the need to take into account how these factors are impacting the individual, as well as how they will be able to continue to function with the sense of uncertainty and turmoil being experienced. As Sajnani and Kaplan (2012) emphasized: "without identifying and inquiring about complex sources of harm, we may risk interpreting one's struggle as a failure on their part, a sentiment that is often euphemized as a 'lack of resilience'” (p. 165).

While it was noted that attitudes toward seeking therapy and counseling seems to be changing, there were still barriers reported to be inhibiting people from accessing mental health care. As indicated herein, art therapy is gradually being used for self-care and mental health promotion, as well as for improving well-being. This form of art therapy promotes personal development and change through the way individuals perceive and develop strategies for life situations. This usage moves away from viewing art therapy as just for curative and diagnostic purposes, toward being more of a life enhancing and empowering tool. While this study has provided a preliminary exploration into how art therapy is being used in Ukraine, further research is required to examine the possible long-term benefits and widespread impact that this approach can have. 


\section{Compliance with Ethical Standards}

Conflict of Interest In accordance with the requirements for submission to the International Journal for the Advancement of Counselling, the authors have no conflict of interest with this manuscript.

\section{References}

Attkisson, C. C., \& Greenfield, T. K. (2004). The UCSF client satisfaction scales: I. The client satisfaction questionnaire-8. In M. Maruish (Ed.), The use of psychological testing for treatment planning and outcome assessment (3rd ed., pp. 799-811). Mahwah, NJ: Lawrence Erlbaum associates.

Arrington, D. (2005). Global art therapy training- now and before. The Arts in Psychotherapy, 22(3), $193-203$. doi:10.1016/j.aip.2005.03.006.

Arrington, D., \& Yorgin, P. (2001). Art therapy as a cross-cultural means to assess psychosocial health in homeless and orphaned children in Kiev. Art Therapy: Journal of the American Art Therapy Association, 18(2), 80-88. doi:10.1080/07421656.2001.10129748.

Bowen, D. (2011). An initial Christian counselor internship program for Ukraine. Journal of Psychology and Theology, 39(4), 356-363 Retrieved from http://www.thefreelibrary. com/An+initial+Christian+counselor+internship+program+for+Ukraine.-a0278526794.

Darwych, O. (2009). Art therapy travels to Ukraine; brief group therapy with orphans. Canadian Art Therapy Association Journal, 22(1), 11-19. doi:10.1080/08322473.2009.11432314.

Darwych, O. (2013). Building bridges with institutionalized orphans in Ukraine: An art therapy pilot study. The Arts in Psychotherapy, 40(1), 85-93. doi:10.1016/j.aip.2012.10.001.

ECArTE. (2015). European Consortium for Arts Therapies in Education. Retrieved from http://www.ecarte. info/membership/directory/-queen-margaret-university-edinburgh.htm.

Feen-Calligan, H., \& Nevedal, D. (2008). Evaluation of an art therapy program: Client perceptions and future directions. Art Therapy: Journal of the American Art Therapy Association, 25(4), 177-182. doi:10.1080 /07421656.2008.10129544.

Feen-Calligan, H., McIntire, B., \& Sands-Goldstein, M. (2009). Art therapy applications of dolls in grief recovery, identity, and community service. Art Therapy: Journal of the American Art Therapy Association, 26(4), 167-173. doi:10.1080/07421656.2009.10129613.

Havenaar, J. M., Meijler-Iljina, L., van den Bout, J., \& Melnikov, A. V. (1998). Psychotherapy in Russia. American Journal of Psychotherapy, 52(4), 501-514.

Henshaw, E. J., \& Freedman-Doan, C. R. (2009). Conceptualizing mental health care utilization using the health belief model. Clinical Psychology: Science and Practice, 16(4), 420-448. doi:10.1111/j.14682850.2009.01181.x.

Larsen, D. L., Attkisson, C. C., Hargreaves, W. A., \& Nguyen, T. D. (1979). Assessment of client/patient satisfaction: Development of a general scale. Evaluation and Program Planning, 2(3), 197-207. doi:10.1016 /0149-7189(79)90094-6.

Linesch, D. (2016). Art therapy with adolescents. In D. E. Gussak \& M. L. Rosal (Eds.), The Wiley handbook of art therapy (pp. 90-98). West Sussex, UK: Wiley Blackwell.

Mauro, M. (2005). The use of art therapy in identity formation. In A. R. Hiscox \& A. C. Calisch (Eds.), Tapestry of cultural issues in art therapy (4th ed., pp. 134-153). Philadelphia, PA: Jessica Kingsley.

McGann, E. (2006). Color me beautiful. Journal of Emotional Abuse, 6(2), 197-217. doi:10.1300/J135v06 n02_ 12.

Miller, G. (2012). Art therapy with adolescents. In C. A. Malchiodi (Ed.), Handbook of art therapy (2nd ed., pp. 241-257). New York, NY: The Guilford Press.

Nikolayenko, O. (2011). Citizens in the making in post-soviet states. New York, NY: Routledge.

Parisian, K. (2015). Identity formation: Art therapy and an adolescent's search for self and belonging. Art Therapy: Journal of the American Art Therapy Association, 32(3), 130-135. doi:10.1080 /07421656.2015.1061257.

Riabchuk, M. (2015). 'Two Ukraines' reconsidered: The end of Ukrainian ambivalence? Academy of Science of Ukraine, 15(1), 138-156. doi:10.1111/sena.12120.

Sajnani, N., \& Kaplan, F. (2012). The creative arts therapies and social justice: A conversation between the editors of this special issue. The Arts in Psychotherapy, 39(3), 165-167. doi:10.1016/j.aip.2011.12.003.

Sosland, A. (1997). The state of psychotherapy in Moscow. International Journal of Psychotherapy, 2(2), $229-234$.

Stoll, B. (2005). Growing pains: The international development of art therapy. The Arts in Psychotherapy, 32(3), 171-191. doi:10.1016/j.aip.2005.03.003. 
Targum, S. D., Chaban, O., \& Mykhnyak, S. (2013). Psychiatry in the Ukraine. Innovations in Clinical Neuroscience, 10(4), 41-46.

Tuchynska, S. (2010). The healing power of art \& music. Kyiv Post. Retrieved from http://www.kyivpost. com/guide/about-kyiv/the-healing-power-of-art-music-89685.html.

Tuchynska, S. (2015, September 28). [Facebook message correspondence]. Retrieved from https://www. facebook.com/messages/svitlana.tuchynska.

Vozneseska, O. (2015 September 16). [Facebook message correspondence]. Retrieved from https://www. facebook.com/messages/voznesenska.olena.

Wood, C. (2013). In the wake of the Matisse RCT: What about art therapy and psychosis? International Journal of Art Therapy: Formerly Inscape, 18(3), 88-97. doi:10.1080/17454832.2013.850104.

Yakushko, O. (2005). Mental health counseling in Ukraine. Journal of mental health counseling. Retrieved from http://www.thefreelibrary.com/Mental+health+counseling+in+Ukraine.-a0132162679.

Yakushko, O. (2007). Career development issues in the former USSR implications of political changes for personal career development. Journal of Career Development, 33(4), 299-315. doi:10.1177 /0894845307300411.

Yakushko, O., \& Sokolova, O. (2010). Work hope and influences of the career development among Ukrainian college students. Journal of Career Development, 36(4), 310-323. doi:10.1177/0894845309345670.

Yankovsky, S. (2011). Neoliberal transitions in Ukraine: The view from psychiatry. Anthropology of East Europe Review, 29(1), 35-49. 